\title{
CRESCIMENTO DE MUDAS DE Anadenanthera falcata, EM CASA-DE-VEGETAÇÃO, INOCULADAS COM RIZÓBIO E MICORRIZAS
}

\section{GREENHOUSE INITIAL GROWTH OF Anadenanthera falcata INOCULATED WITH RHIZOBIA AND MYCHORRIZAL FUNGI}

\author{
Almeida, A. F. ${ }^{1}$; Raymundo-Júnior, O. ${ }^{2}$ \\ ${ }^{1}$ Aluno do curso de Pós-Graduação da Unesp - Rio Claro/SP. \\ ${ }^{2}$ Professor do curso de Ciências Biológicas da Uniararas - Araras/SP \\ Correspondência: afa_micro@yahoo.com.br
}

\section{RESUMO}

Estudo realizado em casa-de-vegetação, as sementes de Anadenanthera falcata (Benth.) Speg. (angico-do-cerrado) foram inoculadas com rizóbio e esporos de fungos micorrízicos para testar o crescimento de mudas em solo obtido de uma área desmatada de cerrado "sensu strictu". As mudas foram monitoradas mensalmente por doze meses, medindo-se altura, número de folhas e diâmetro do caule. Os resultados obtidos mostraram que a dupla inoculação com rizóbio e fungos micorrízicos melhoraram a formação de nódulos no sistema radicular em $341 \%$ e a colonização por micorrizas/cm de raiz em $226 \%$. Diferenças foram observadas no crescimento de plantas com respeito à altura, diâmetro do caule e peso seco de folhas, caule e raízes quando comparado inoculação com rizóbio ou rizóbio + fungos micorrízicos.

Palavras chaves: Anadenanthera falcata, micorriza, rizóbio, angico-do-cerrado.

\section{ABSTRACT}

In a study carried out in a greenhouse, seeds of Anadenanthera falcata (Benth.) Speg. (angico-do-cerrado) were inoculated with rizobia and mycorrhizal fungi spores to test the growth of the plantlets in soil obtained in a deforested area of cerrado "sensu strictu". The plantlets were monitored monthly for twelve months, measuring height, number of leaves, and diameter of the stalk. The results obtained showed that 
the double inoculation with rizobia and mycorrhizal fungi improved the formation of nodules in the root system by $341 \%$ and the colonization by mycorrhizal $/ \mathrm{cm}$ of root by $226 \%$. Differences were observed in growth of plants with respect to the height, stalk diameter and dry weight of leaf, stalk and roots when comparing inoculation with rizobia or rizobia + mycorrhizal fungi.

Keys words: Anadenanthera falcata, mycorrhizal fungi, rizobia, angico-do cerrado.

\section{INTRODUÇÃO}

Interações mutualísticas entre plantas, micorrizas e bactérias fixadoras de nitrogênio têm sido uma alternativa econômica para a implantação de programas de recuperação de solos degradados, nos quais o desenvolvimento do sistema radicular é limitado pelas condições edáficas. Os microrganismos simbiontes permitem ao sistema radicular, explorar maior volume de solo, fixar nutrientes em forma de biomassa e absorver nutrientes com baixa mobilidade que limitariam o desenvolvimento vegetal, além de atenuar a toxidez de alguns elementos presentes no solo que seriam tóxicos às plantas e favorecendo o restabelecimento da comunidade microbiana no solo (NOGUEIRA, 2002).

Fatores abióticos presentes no ambiente de desenvolvimento da planta, como $\mathrm{pH}$, ausência ou presença de metais em grandes quantidades, umidade, disponibilidade de nutrientes essenciais como $\mathrm{N}$, $\mathrm{P}$ e $\mathrm{K}$, podem interferir no desenvolvimento do sistema radicular do vegetal causando sintomas visíveis nas folhas ou mesmo no próprio sistema radicular (SAINI et al., 2004). A colonização micorrízica nas raízes de muitas famílias de plantas aumenta a absorção de fósforo do solo pelo vegetal, o que permite, algumas vezes, efeitos sinergísiticos observados quando micorriza e rizóbio estão presentes, aumentando a fixação do nitrogênio.

As ferramentas genéticas para a explicação destes mecanismos de interação entre planta - fungo micorrízico - rizóbio ainda são escassas para o entendimento do reconhecimento do hospedeiro compatível, o processo de penetração da raiz ou transferência de nutrientes com o hospedeiro, sendo desconhecida a dinâmica e a regulação do nível de interação da população microbiana com a comunidade vegetal (PAWLOWSKA, 2005). Porém, é sabido que os microrganismos adaptados a um ambiente de crescimento, possuem maiores chances de efetivar a infecção na raiz e estabelecer a transferência de nutrientes para o vegetal entre os microrganismos envolvidos na fixação do nitrogênio.

$\mathrm{O}$ estabelecimento da produção de mudas com a utilização de inóculos adaptados aos fatores biótico e abiótico podem ser uma alternativa para o aumento do sucesso de recuperação de áreas degradadas, ocorrendo maior número de plantas sadias juntamente com o restabelecimento de condições para recompor a diversidade 
microbiana. Este estudo foi implantado em casa-de-vegetação não havendo controle de pragas, fornecimento de nutrientes ou controle de água fornecida às plantas. $\mathrm{O}$ objetivo deste trabalho foi avaliar o crescimento de mudas de Anadenanthera falcata (Benth.) Speg. colonizadas por fungos micorrízicos e rizóbio, com o uso de inóculos obtidos do sistema radicular de plantas da mesma espécie, localizada em área de cerrado sensu stricto.

\section{MATERIAL E MÉTODOS}

O experimento foi realizado em casa-de-vegetação localizada no Centro Universitário Hermínio Ometto - Uniararas, na cidade de Araras/SP, de janeiro a dezembro de 2001. O solo usado para a produção de mudas foi do tipo Latossolo vermelho-amarelo, textura arenosa, coletado na região de cerrado da Reserva Biológica de Mogi Guaçu - Fazenda Campininha, no Bairro de Martinho Prado, na cidade de Mogi Guaçu/SP localizada a S $22^{\circ} 15^{\prime} 065^{\prime \prime}$ e W 47 09'491'.

A partir de $10 \mathrm{~kg}$ de solo obtido da rizosfera de cinco plantas adultas da espécie Anadenanthera falcata (Benth.) Speg., até a profundidades de $20 \mathrm{~cm}$, concentrou-se 260 esporos/mL de fungos micorrízicos arbusculares (FMA), isolados pelo método de Melo e Sanhueza (1995), predominando Glomus sp, Glomus etunicatum, Glomus melanosporum, Acaulospora denticulata, Acaulospora lacunos, Gigaspora sp e Gigaspora dexcipiens.

O inóculo de rizóbio foi isolado a partir de nódulos de mudas de A. falcata cultivadas em casa-de-vegetação. A desinfecção dos nódulos foi realizada com hipoclorito de sódio a $5 \%$ por dois minutos, lavados oito vezes com água destilada e álcool $70 \%$ por cinco minutos e lavados com água destilada. O rizóbio foi isolado em meio de extrato de levedura-manitol (Yeast-manitol). As sementes e os nódulos foram desinfetados seguindo o mesmo procedimento e embebidas, por duas horas, em meio semi-sólido (Yeast-manitol) contendo cultura de rizóbio. A inoculação com esporos de FMA foi realizada utilizando-se $5 \mathrm{~mL}$ da solução de esporos, colocados diretamente sobre as sementes. As mudas foram cultivadas em sacos de polietileno preto com capacidade de $500 \mathrm{~g}$, contendo amostras de solo in natura obtidas da superfície (até $20 \mathrm{~cm}$ ). As amostras foram analisadas no laboratório de análises químicas de solo e planta da UFSCar, campus de Araras/SP, obtendo-se em $\mathrm{mmol}_{\mathrm{c}} / \mathrm{dm}^{3}$ : K 0,8; Ca 40,0; Mg 16,0; H+AL 13,0; SB 56,8; CTC 69,8; em mg/dm :Cu 2,6; Fe 32,0; Mn 9,4; Zn 1,6; S 6,0 e pH 6,2. Foram colocadas duas sementes por saco plástico, com os seguintes tratamentos: Controle (C), Inoculação com Rizóbio (R) e Inoculação com Micorriza + Rizóbio (MR), em 40 repetições.

Foram avaliados o crescimento em altura (em $\mathrm{cm}$ e massa seca), número de folhas, diâmetro do caule e número de nódulos. A porcentagem de colonização de micorriza nas raízes foi determinada pelo método de Giovannetti et al. (1980). A análise estatística utilizou Anova e o Teste de Tukey. 


\begin{tabular}{|l|r|}
\hline Recebido em: 05/04/2005 & HOLOS Environment, v.6 n.1, 2006 - P. 25 \\
\hline Liberado para Publicação em: $29 / 06 / 2006$ & ISSN: 1519-8634 \\
\hline
\end{tabular}

\section{RESULTADOS E DISCUSSÃO}

A inoculação de fungos micorrízicos (FMA) e rizóbio no tratamento $\mathrm{MR}$ proporcionou aumentos em altura, número de folhas e no diâmetro do colo de $A$. falcata (FIGURA 1) correspondentes a $72 \%, 71 \%$ e 15\%, respectivamente. Para o tratamento $\mathrm{R}$ verificou-se crescimento de $41 \%$ em altura, 22\% no número de folhas e 4,7\% no diâmetro do colo (TABELA 1). Burity et al. (2000) observaram crescimento de 28,64 cm em altura no tratamento em que se inoculou rizóbio, e de 61,10 cm no tratamento em que se inoculou micorriza e rizóbio, e aumentos na produção de massa seca da parte aérea de 1,24 g/saco e 12,39 g/saco nos tratamentos em que se inoculou somente rizóbio e micorriza e rizóbio, respectivamente, nas plantas Mimosa caesalpiniifolia.

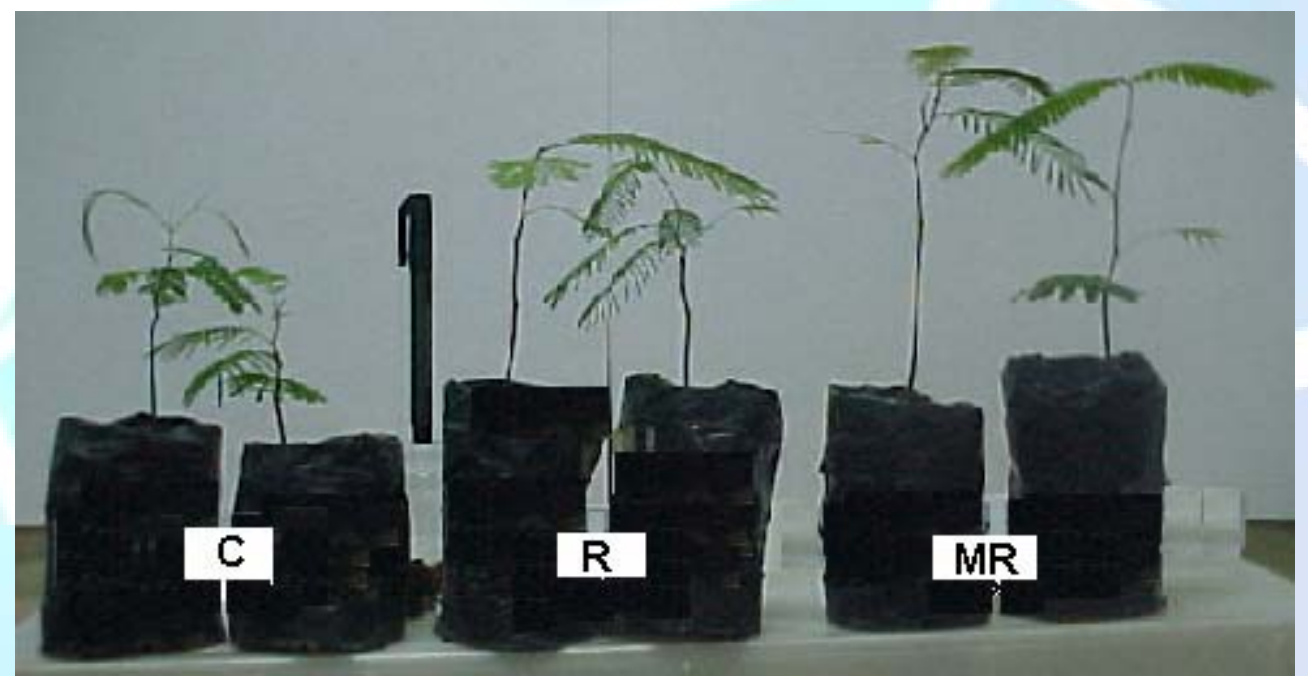

FIGURA 1 - Mudas de Anadenanthera falcata com doze meses de cultivo em Latossolo Vermelho Amarelo, textura arenosa, em casa-de-vegetação. (C) controle, (R) inoculação com rizóbio e (MR) inoculação de fungos micorrízicos e rizóbio.

O xilopódio das plantas de $A$. falcata, mencionado como raiz, apresentou valores $7,81 \mathrm{~cm}$ de comprimento, $9,51 \mathrm{~mm}$ de diâmetro e matéria seca $3,08 \mathrm{~g} / \mathrm{ps}$ no tratamento $\mathrm{R}$, os quais foram superiores aos obtidos no tratamento MR, respectivamente $6,82 \mathrm{~cm}, 8,18 \mathrm{~mm}, 2,76 \mathrm{~g} / \mathrm{os}$ (TABELA 1). Gross et. al (2004), utilizando solo não autoclavado, observaram redução de massa seca do xilopódio, devido aos elevados valores na taxa de colonização micorrízica e de nodulação em virtude do provável dreno de carboidratos desse órgão de armazenamento para os fungos micorrízicos e rizóbios nativos. Estes resultados corroboram os que foram obtidos neste trabalho para a biomassa do xilopódio e justificam os valores significativos maiores obtidos para a massa seca de folhas e caule em relação ao controle e tratamento R, os quais também foram obtidos por Rodrigues et al. (2003). Estes autores utilizaram solo não esterilizado e observaram que a colonização micorrízica e rizóbio gerou crescimento significativo em Sesbania virgata de 13,0 g 
com inoculação de micorriza e sem rizóbio e de 15,0 g com inoculação de micorriza e rizóbio na massa seca da parte aérea e de $5,5 \mathrm{~g}$ com inoculação de micorriza e sem rizóbio e de 5,1 g com inoculação de micorriza e com rizóbio na massa seca de raízes.

A nodulação no tratamento $\mathrm{R}$ ocorreu em todo o sistema radicular com nódulos de comprimento de $4,67 \mathrm{~mm}$ e diâmetro de $1,37 \mathrm{~mm}$ e, enquanto que no tratamento MR, a mesma concentrou-se nas raízes próximas ao xilopódio com comprimento de $5,15 \mathrm{~mm}$ e diâmetro de $1,72 \mathrm{~mm}$, sempre na forma de cachos contendo de dois a cinco nódulos. Estes resultados demonstram que no tratamento MR ocorreu formação de nódulos precocemente, enquanto que no tratamento $\mathrm{R}$ a nodulação ocorreu tardiamente por alguns fatores não observados neste experimento. Burity et al. (2000) obtiveram aumento de massa seca dos nódulos com inoculação rizóbio + micorriza de $175,5 \mathrm{mg} / \mathrm{saco}$ em solo previamente esterilizado o qual recebeu dosagens de $\mathrm{P}_{2} \mathrm{O}_{5}$.

$\mathrm{O}$ controle apresentou 0,28 nódulos/planta, os tratamentos R 2,83 e MR 4,66 nódulos/planta, resultando em aumento de $156 \%$ e $226 \%$, respectivamente. Os nódulos encontrados no tratamento $\mathrm{C}$ apresentaram-se inviáveis. Nos tratamentos $\mathrm{R}$ e MR verificou-se $35 \%$ e $95 \%$ dos nódulos viáveis, respectivamente, com crescimento apical visível e coloração vermelha típica de nódulos ativos, devido à presença de leg-hemoglobina. Gross et al. (2004) afirmam que a nodulação no tratamento com inoculação de micorriza e rizóbio é maior devido a absorção de fósforo e este por ser translocado pelas hifas à planta pode influenciar positivamente o estabelecimento e a ocorrência de nódulos. Em leguminosas a interação entre micorriza e rizóbio leva a um metabolismo mais elevado quando comparado com as plantas não micorrizadas, fornecendo maior quantidade de carboidratos e fósforo ao rizóbio e, conseqüentemente, essas plantas apresentam uma nodulação significativamente maior (SILVEIRA et al., 1995).

TABELA 1. Valores do crescimento em altura, número de folhas, diâmetro do caule e massa seca de Anadenanthera flacata (Benth.) Speg. sob tratamentos controle (C), inoculação de rizóbio (R) e inoculação de fungos micorrízicos e rizóbio (MR) após doze meses de cultivo em casa-devegetação (Médias de quarenta repetições)

\section{Características}

\begin{tabular}{lccc}
\hline \multirow{2}{*}{ Características } & $\mathbf{C}$ & Tratamentos \\
\cline { 2 - 4 } & & $\mathbf{R}$ & MR \\
\hline & $9,73 \mathrm{~b}$ & Desenvolvimento & $16,70 \mathrm{a}$ \\
Altura $(\mathrm{cm})$ & $3,27 \mathrm{~b}$ & $13,72 \mathrm{~b}$ & $5,60 \mathrm{a}$ \\
Número de Folhas & $1,48 \mathrm{a}$ & $4,00 \mathrm{~b}$ & $1,70 \mathrm{a}$ \\
Diâmetro $(\mathrm{mm})$ & & $1,55 \mathrm{a}$ &
\end{tabular}

\begin{tabular}{lccc} 
& & Massa Seca (g) & $0,29 \mathrm{a}$ \\
Caule & $0,20 \mathrm{~b}$ & $0,26 \mathrm{~b}$ & $0,38 \mathrm{a}$ \\
Folhas & $0,24 \mathrm{~b}$ & $0,31 \mathrm{~b}$ & $2,76 \mathrm{~b}$ \\
Raiz (xilopódio) & $1,85 \mathrm{~b}$ & $3,08 \mathrm{a}$ & $\mathrm{a}$ \\
\hline
\end{tabular}

Média seguida de mesma letra na mesma linha não diferem entre si pelo teste de Tukey a 5\% de probabilidade. 
Os teores de nitrogênio dos tratamentos não foram significativamente diferentes entre si (TABELA 2). Siqueira e Franco (1998) verificaram diminuição na porcentagem de nitrogênio nas plantas, devido à diluição deste nutriente nos fungos, ocorrendo aumento da biomassa micorrízica e diminuição da concentração de nitrogênio na massa seca da planta. Resultados semelhantes foram obtidos em outros trabalhos, nos primeiros meses de cultivo, nas mudas colonizadas por fungos micorrízicos (TRIMBLE e KNOWLES, 1995; JOHANSEN, 1999).

$\mathrm{O}$ teor de fósforo foi maior no tratamento MR, mostrando efeito benéfico da colonização micorrízica. A importância das micorrizas para a absorção de fósforo pela planta é demonstrada em diversos trabalhos, assim como os seus mecanismos fisiológicos, justificando o maior crescimento nos estágios iniciais (FLORESAYLAS et al., 2003; MUNRO et al.,1999; POUYU-ROJAS e SIQUEIRA, 2000; SAINI et al., 2004).

TABELA 2. Teores de P, N, Ca, Mg, K, S, Fe e Zn de Anadenanthera falcata (Benth.) Speg. sob tratamento controle $(\mathrm{C})$, inoculação com rizóbio $(\mathrm{R})$ e inoculação com micorriza e rizóbio (MR), após doze meses de cultivo em Latossolo Vermelho Amarelo, textura arenosa, em casa-devegetação.

\begin{tabular}{|c|c|c|c|c|c|c|c|c|}
\hline \multirow{2}{*}{ Tratamentos } & $\mathbf{P}$ & $\mathbf{N}$ & $\mathrm{Ca}$ & Mg & $\mathbf{K}$ & \multirow[t]{2}{*}{$\mathbf{S}$} & $\mathrm{Fe}$ & Zn \\
\hline & \multicolumn{5}{|c|}{ (\%/biomassa) } & & \multicolumn{2}{|c|}{ ppm/biomassa } \\
\hline C & $0,63 \mathrm{a}$ & $0,65 \mathrm{a}$ & $1,00 \mathrm{a}$ & $0,24 \mathrm{a}$ & $1,30 \mathrm{a}$ & $1,11 \mathrm{a}$ & $525 \mathrm{a}$ & $26 a$ \\
\hline $\mathbf{R}$ & $0,65 a, b$ & $0,65 a$ & $0,95 \mathrm{a}$ & $0,21 \mathrm{a}$ & $1,50 \mathrm{a}$ & $0,63 a$ & $610 \mathrm{a}$ & $85 b$ \\
\hline MR & $0,72 b$ & $0,60 \mathrm{a}$ & $1,27 b$ & $0,26 \mathrm{a}$ & $1,30 \mathrm{a}$ & $1,26 b$ & $525 a$ & $27 \mathrm{a}$ \\
\hline
\end{tabular}

Médias seguidas de mesma letra na mesma coluna não diferem entre si pelo teste de Tukey a $5 \%$ de probabilidade.

Os minerais $\mathrm{Ca}, \mathrm{Zn}$ e $\mathrm{S}$ apresentaram diferenças significativas nos tratamento $\mathrm{R}$ e MR (TABELA 2). As variações nos teores de nutrientes na biomassa vegetal de plantas inoculadas com rizóbio e micorriza, em casa-de-vegetação (NOGUEIRA e CARDOSO, 2002) e em áreas contaminadas por metais pesados (SIQUEIRA et al, 1999) não foram conclusivas quanto ao papel dos mesmos na tríplice simbiose.

\section{CONCLUSÕES}

A inoculação com rizóbio e fungos micorrízicos aumentou o crescimento em altura e número de folhas e da parte aérea em $A$. falcata.

O desenvolvimento radicular (xilopódio) foi menor no tratamento MR comparado ao tratamento $\mathrm{R}$.

No tratamento MR observou-se maior número de nódulos viáveis por planta. 
Ocorreram aumentos significativos nos teores de $\mathrm{P}, \mathrm{Ca}, \mathrm{S}$ e $\mathrm{Zn}$ nos tratamentos $\mathrm{R}$ e MR.

A técnica de inoculação de mudas de leguminosa arbórea $A$. falcata, em casa de vegetação, com rizóbio e esporos de fungos micorrízicos, isolados da rizosfera de plantas adultas da mesma espécie, em ambiente de cerrado, promoveu melhora do crescimento e desenvolvimento destas mudas.

\section{AGRADECIMENTOS}

À Profa. Dra. Lázara Cordeiro (Depto. Botânica - Unesp/Rio Claro), Profa. Silvana Perissato Meneghim (UFSCar/Araras), Raquel Salomão Remédio (Laboratório de Microbiologia - Uniararas/Araras) e Enga . Márcia Maria Rosa por terem colaborado com este trabalho.

\section{REFERÊNCIAS}

BURITY, H.A.; VASCONCELOS, L.; FREIRE, V.F. Efeito de níveis de fosfatos de rocha e da inoculação de Rhizobium sp. e Glomus macrocarpum Tul. sobre o desenvolvimento de jurema preta, Mimosa acustistipula Benth. Pesq. Agropec. Bras., Brasília, v. 35, n.4, p. 801-807, 2000.

FLORES-AYLAS, W.W.; SAGGIN-JÚNIOR, O.J.; SIQUEIRA, J.O.; DAVIDE, A.C. Efeito de Glomus etunicatum e fósforo no crescimento inicial de espécies arbóreas em semeadura direta. Pesq. Agropec. Bras., Brasília, v.28, n. 2, p. 257-266, 2003.

GIOVANNETI, M.; MOSSE, B. An evaluation of techiniques for measuring vesicular-arbuscular mycorrhizal infections in roots. New Phytology, Oxford, v.84, p. 489-500. 1980.

GROSS, E.; CORDEIRO, L. CAETANO, F.H. Nodulação e micorrização em Anadenanthera peregrina var. falcata em solo de cerrado autoclavado e não autoclavado. Rev. Bras. Ci. Solo, Campinas, v. 28, p. 95-101, 2004.

JOHANSEN, A. Depletion of mineral N by roots of Cucumis sativus L. colonized or not by arbuscular mycorrhizal fungi. Pant and Soil, The Hague, v: 209, p. 119-127, 1999. 
MELO, I.S.; SANHUEZA, R.M.V. (Coord.) Métodos de seleção de microrganismos antagônicos a fitopatógenos: Manual Técnico. EMBRAPACNPMA, Jaguariúna. 1995, p.72.

MUNRO, R.C.; WILSON, J.; JEFWA, J.; MBUTHIA, K.W. A lost-cost method of mycorrhizal inoculation improves growth of Acacia tortilis seedlings in the nursery. For. Ecol. Manag., Elsevier, v. 133, p. 51-56, 1999.

NOGUEIRA, M.A.; CARDOSO, E.J.B.N. Interações microbianas na disponibilidade e absorção de manganês por soja. Pesq. Agropec. Bras., Brasília, v. 37, n.11, p. $1605-$ $1612,2002$.

PAWLOWSKA, T. E. Genetic processes in arbuscular mycorrhizal fungi. FEMS Microbiol., v. 251, p. 185-192, 2005.

POUYU-ROJAS, E.; SIQUEIRA, J. O. Micorriza arbuscular e fertilização do solo no desenvolvimento pós-transplante de mudas de sete espécies florestais. Pesq. Agropec. Bras., Brasília, v. 35, n. 1, p. 103-114. 2000.

RODRIGUES, L.A.; MARTINS, M.A.; SALOMÃO, M.S.M.B. Uso de micorrizas e rizóbio em cultivo consorciado de eucalipto e sesbânia. I- Crescimento, absorção e transferência de nitrogênio entre plantas. Rev. Bras. Ci. Solo, Campinas, v. 27, p. 583-591, 2003.

SAINI, V.K., BHANDARI, S.C., TARAFDAR, J.C. Comparison of crop yield, soil microbial $\mathrm{C}, \mathrm{N}, \mathrm{P}$ and $\mathrm{N}$-fixation, nodulation and mycorrhizal infection in inoculated and non-inoculated sorghum and chickpea crops. Field Crops Res., Amsterdam, v.89, p. 39-47, 2004.

SILVEIRA, A.P.D.; FREITAS, S.S.; SILVA, L.R.C. LOMBARDI, M.L.C.O.; CARDOSO, E.J.B.N. Interações micorrízicas arbusculares e rizobactérias promotoras do crescimento em plantas de feijão. Rev. Bras. Ci. Solo, Campinas, v. 19, p. 205$211,1995$.

SIQUEIRA, J. O.; FRANCO, A.A. Microbiologia do Solo: fundamentos e perspectivas.Brasília: MEC; Lavras: ESAL, FEPE, 1998, 236p.

SIQUEIRA, J.O.; PEREIRA, M.A.M.; SIMÃO, J.B.P.; MOREIRA, F.MS. Efeito da formononetina (7 hidroxi, 4'metoxi Isoflavona) na colonização do milho em solo contento excesso de metais pesados. Rev. Bras. Ci. Solo, Campinas, v. 23, p. 561$567,1999$. 
TRIMBLE, M. R.; KNOWLES, N. R. Influence of vesicular-arbuscular mycorrhizal fungi and phosphorus on growth, carbohydrato partitioning and mineral nutrition of greenhouse cucumber (Cucumis sativus L.) plants during establishment. Can. Jour. Plant. Sci., Ottawa, v.75, p. 239-250, 1995. 